\title{
Family-Centred Care in Paediatric and Neonatal Nursing- A Literature Review
}

L K Irlam, BSc Nursing (UCT), MSc Nursing Student, Department of Nursing Education University of the Witwatersrand

J C Bruce, MSc Nursing (Wits), Senior Lecturer, Department of Nursing Education University of the Witwatersrand

\begin{abstract}
A literature review of family-centred care in paediatric and neonatal nursing was undertaken as part of a research project. This research intended to ascertain the knowledge and attitudes of paediatric and neonatal qualified nurses and nurse educators towards family-centred care as it pertains to infants and children in hospitals in the Gauteng Province. A definition of family-centred care is difficult to formulate mainly due to the lack of consensus about its meaning. Additionally, the diverse societal contexts within which family-centred care is applied further complicate its definition. Internationally in developed countries, family-centred care is viewed as care, which is parent-led in consultation with the nurse practitioner. A family-centred care model for the South African context needs to be developed with the focus on parent participation, a precursor of family-centred care. This article traces the early developments in parental care for hospitalised children with specific reference to the USA, the UK and South Africa. Precursor concepts in family-centred care are described followed by a cursory overview of the reality of family-centred care, its cultural dimensions and matters of family strengths and choices in family-centred care.
\end{abstract}

\section{Introduction}

Family-centred care is being explored overseas as care that is parent-led with the nurse acting as a consultant or counsellor, fostering open, honest dialogue with the family, especially with the parents in the case of family-centred paediatric and neonatal nursing. The family is acknowledged as experts in the care of their child and their knowledge and skills are respected. Since no literature could be found on the early developments in parental care for hospitalised children and minimal literature on the development of family-centred care for infants and children in South Africa, mainly overseas literature sources were consulted.

This is unfortunate, as families have evolved differently in developed and culturally distinctive (predominantly AngloSaxon) societies such as the USA or the UK in comparison to South Africa, which comprises families representing both first and third world countries' families. Most of the literature sources were drawn from these two countries. The dearth of literature on family-centred practices in hospitals in developing countries could be explained by the trend in recent decades towards home-based care. As developing countries have fewer resources, the advent of Primary Health Care (PHC) with its emphasis on home-based care has been welcomed with enthusiasm. In the case of paediatric and neonatal care, many patients however, may require hospitalisation. Hence the involvement of families in the care of their hospitalised children is essential to facilitate continued care for their children at home.

\section{Early developments in parental care for hospitalised children}

Brewis (1986:34) states that "in years gone by parents relinquished responsibility for their child at the ward doors (if not before): a fait accompli. The child became the jealous property of the nurses and doctors, with access by parents being tolerated weekly, eventually daily, but usually grudgingly." In contrast however, as early as the mid-1700's, dispensaries existed, which gave advice and medicine to parents who consulted them. The first of these was opened by George Armstrong, a distinguished physician who believed that children should not be separated from their parents by admission to hospital, claiming prophetically that, "the mothers and the nurses would be constantly at variance with each other"(Miles in Darbyshire, 1993: 1671). This author also stated that taking a sick child away from its parents, or equivalent substitute, "breaks its heart immediately" (Burgess, 1988:70). There was, therefore, recognition that physical separation of a child from the parent or carer has serious psychological implications for the child.

The predominance of infectious diseases and fatal illnesses created a rigid hospital environment based on strict asepsis and routine. This system was to affect the relationships between hospital staff, children and parents for over a century and is still apparent today (Darbyshire, 1993). According to Darbyshire (1993:1671), "the ethos of child care within the paediatric hospitals was not shaped solely by physical and epidemiological factors." The child-rearing ideologies of the early twentieth century further fostered a mechanistic and regi- 
mented care by its emphasis on a cold, detached relationship with children.

Research over the last 50 years has shown the detrimental effect on children of separation from their parents during hospitalisation. A major influence in changing attitudes towards the care of children in the 1950's, was the work of John Bowlby and later, James Robertson (Swanwick, 1983). John Bowlby, a child psychiatrist, was an appointed mental health consultant at to the World Health Organisation (WHO) in 1950. In a book written while in this post, he expressed the belief that a warm, intimate and continuous relationship with the mother or person who steadily mothers, is essential for the mental health of the infant and young child. He continued by saying that it is this complex and rewarding relationship in the early years, varied in countless ways by relations with the father, brothers and sisters, that child psychiatrists and many others now believe to underlie the development of character and mental health. These views were extremely controversial; complete strangers were nursing children and visiting in hospitals by family was usually very restricted (Swanwick, 1983). James Robertson, a psychoanalyst, filmmaker and campaigner revealed in his studies of children before, during and after hospital admission, that children experience 'separation anxiety,' evidenced by three identifiable stages: initially protest at being deserted; despair when their protestations are fruitless; and finally denial, leading to depression and withdrawal (Palmer, 1993; Swanwick, 1983).

\section{United Kingdom}

As evidence of numerous studies grew, pressure mounted for a change in attitudes towards the care of sick children (Swanwick, 1983). In 1956, the Platt Committee was set up to make a special study of the arrangements made in hospitals for the welfare of sick children (Swanwick, 1983). The Platt report (The Welfare of Children in Hospital, The Ministry of Health and Central Health Services Council, 1959) was published in 1959 and was revolutionary in its recommendations (Darbyshire, 1993). It highlighted the fact that the hospital is a 'strange environment' for a child and the circumstances such, that children are likely to experience pain and distress. It advocated respect for the authority of parents in handling their child and encouraged admission of the mother with the child to hospital. Wherever possible, home-based care was promoted as a preferred alternative to hospitalisation. The report also advocated that children's nurses should be specifically trained to care for children and that children should be nursed in an environment supportive of complete child development. Those campaigning and concerned for the welfare of children in hospital enthusiastically welcomed the report. (Darbyshire, 1993; Swanwick, 1983). However, the implementation of the Platt report's recommendations was very slow (Palmer, 1993). Hall (1978) argued that this "was due to the fact that the report had considered only psychological theory, that is, mother-child separation. The report had ignored the wider sociological implications of hospitals as institutions, and the difficulty inherent in effecting change within them. Hall (1978) also argued that having parents in the ward as visitors or residents, created resistance from staff who did not accept that parents should be there (Darbyshire, 1993: 1672). Staff still needed to be convinced by the evidence that parental presence with ill children is a good practice.

\section{United States of America}

In 1967 only 28 of the 5000 general hospitals in the United States had facilities for parents to spend the night with their child. Despite the recommendation of the American Academy of Paediatrics in 1971 that hospitals should provide facilities to promote the well being of both the parents and the child (Hardgrove \& Roberts, 1989), the USA lagged behind many countries in such provisions. A study conducted in 1978 (Hardgrove \& Roberts, 1989) identified a gap between research-based rationale encouraging parents to stay with their child and the style of implementing 'living-in' programs. Results of the survey indicated that institutional support of parental presence was, for the most part, confined to providing accommodation for parents of children who had been admitted. Few hospitals provided services for psychological and family support or helped with parent-to-parent peer support groups. In contrast to the UK however, there is no national policy requiring a certain number of parent beds for every childbed on the unit, and there is no general policy granting sick leave to working parents when a child is ill or hospitalised. Despite the lack of national policy it would appear that the Association for the Care of Children in Hospitals, founded by educationalists in 1967, has been instrumental in the further development of parental care for hospitalised children in the USA.

\section{South Africa}

The plethora of research from the UK and USA on familycentred care, the work of associations to promote family-centred care and a separate register for children's nurses to safeguard their special training needs, indicate a commitment at every level in these countries to making family-centred care a reality. In contrast, there is a paucity of research in South Africa pertaining to the care of hospitalised children by the family. Orr (1994) highlighted the plight of children in hospital in this country, by suggesting that many hospitals in South Africa have made little attempt to humanize the stay of young children. She concluded that many nursing and medical personnel in South Africa have either not taken cognisance of the published research or have alternatively, not been convinced of its relevance.

A thorough search of the South African nursing literature was conducted. Bonn (1994), Pillay \& Pillay (1988) and Rangaka, Rose \& Richter (1993) addressed the emotional impact of paediatric hospitalisation but in only two articles (Leary, 1973; Lerwill, 1983), were the needs of the South African child in hospital addressed directly. Leary (1973) observed that the vast majority of the hospital child population in South Africa is poor and 'non-white.' The present situation is no different. Leary (1973) remarked that as the children's physical needs are generally being better catered for in hospital with visible improvement in their condition, psychological needs are often overlooked. He concluded that these children also suffer separation anxiety and therefore their psychological needs should be addressed. (Leary, 1973). Lerwill (1983) discussed a pre-hospital preparation programme in place at an academic hospital in Johannesburg. Family-centred care policies were also mentioned and appeared quite restrictive; it referred to "rooming-in" facilities for mothers of children during long-term hospitalisation and the allowance of siblings with "special consideration". Since 
then several legislative documents have been passed recognising the rights of the child in South Africa, yet the voices of children, parents, families, health care providers and health care workers remain silent.

\section{Evolution of concepts in family- centred care}

The significance of family-centred care will never demise, as long as society recognises the family as pivotal to the growth and development of its members. Current global political, economic and socio-cultural patterns do not always support this premise although it is the ideal. However, the growing body of literature on family-centred care and the commitment by many governments to uphold the rights of children and their families indicate that family-centred care is valued and should be striven for in every human service discipline.

Nurse researchers and educators have become involved in theory development and concept analysis of this "very illdescribed and amorphous" concept that has evolved over the years (Darbyshire, 1993:1672). If family-centred care is to strengthen families and to advance the knowledge and practice of paediatric and neonatal nursing, it is vital that the concept is properly understood. Authors have used various models of concept analysis and concept development to analyse family-centred care and its related concepts (Nethercott, 1993; Cahill, 1996; Coyne, 1996; Hutchfield, 1999).

Cahill (1996) suggests that there is a hierarchical relationship between the concepts of patient involvement and collaboration, which is a precursor to patient participation, which in turn is the precursor to patient partnership. In paediatric nursing, one could substitute "patient" involvement with terms such as collaboration, participation and partnership with "parent", as the child is not capable of self-care and requires a substitute self-care agent (Orem, 1985). In discussing the related concepts of involvement, collaboration, participation and partnership the term "patient" has been substituted by "parent".

\section{Parent involvement and collaboration}

Several authors have confused the arena of nursing children with their families by using the terminology of involvement, collaboration, participation and partnership synonymously (Cahill, 1996). Patient/parent involvement is considered to be a one-way process as the patient's voice is mostly ignored. A narrowing of the knowledge gap between the parent and the nurse is not required, as activities are undertaken in the form of basic delegated tasks. These tasks do not extend to complex intellectual activities such as decision-making. (Cahill, 1996). Parent collaboration implies joint involvement in intellectual activities for the purpose of decisionmaking and is a co-operative endeavour between the parent and the nurse (Cahill, 1996). Like parent participation, it seeks to improve working relationships and patient outcomes, although parent participation is a more comprehensive definition of a relationship with another. Participation requires a narrowing of the appropriate knowledge and/or competence gap between the nurse and parent. It requires surrendering of a degree of control by the nurse and a positive engagement in selective intellectual and/or physical activities by the family during some of the phases of the health care process (Cahill, 1996).

\section{Parent participation}

Coyne (1996) explores the historical development and evolution of parent participation, as he believes it best encompasses the current evidence on family-centred care practice referred to in the literature. From a review of the American and $\mathrm{Ca}$ nadian literature, the description and development of the concept has evolved differently from what has been described in the British literature (Coyne, 1996). This is not surprising considering the cultural differences between the two health care systems, and the influence of socialisation and repeated interaction on the development of a concept (Coyne, 1996). Studies by Webb, Hull \& Madeley (1985) and Keane, Garralda \& Keen (1986) concluded that parent participation was being practiced because parents were involved in performing tasks for their children in hospital. Parent participation is not about whether parents are competent to perform tasks or not but whether there is willingness on the part of parents to perform these tasks or on the part of nurses to teach parents these tasks or procedures. These studies, however, did not explore the meaning of the participation for the parents (Callery \& Smith, 1991; Coyne, 1996; Darbyshire, 1994).

No concept analysis of family-centred care and its precursors could be found in the South African literature. Reflecting on the impact of the cultural differences between health care systems in the UK and the USA on the evolution of the concept, the need to explore a definition of family-centred care that is unique to the South African political and socio-cultural context, was considered to be important.

\section{Parent partnership}

In Cahill's (1996) concept analysis of patient (substitute parent) participation, parent participation is a precursor to parent partnership in the hierarchical order of related concepts. In 1988 Casey viewed parent participation in terms of partnership with parents, and developed the "partnership model of paediatric nursing" (Coyne, 1996). Parent partnership is not unlike parent participation in that it also implies a reciprocal sharing or closeness between the parent and the nurse (Cahill, 1996). Parent partnership, however, demands a working association between two people in a joint venture based upon a contract, which may be verbal or written and which may have advantages and disadvantages (Cahill, 1996:567). Both Stower (1992) and Dearmun (1992) explored the boundaries of the concept "partnership" and concluded that equality and negotiation were central issues in such a partnership (Coyne, 1996:737).

Callery and Smith (1991) and Callery (1997) however questioned the validity of role negotiation between nurses and the parents of hospitalised children since nurses maintain control and hold the initiative in the decision about whether negotiation takes place. Issues of territory, anxiety, uncertainty, control and conflicts arising from parental competence all 
place the parent in a subordinate position. Hence equality too becomes a misnomer in the issue of partnership (Callery \& Smith, 1991:772).

The perception by nurses of family as "interfering" has also been raised in the literature. Robinson \& Thorne (1984) examined the phenomenon of family interference and found that nurses tended not to view caring for the needs of families as a realistic expectation of their role. Interpretations of interfering behaviour include the belief that interference is a natural consequence of a traumatic situation arising out of the disease condition and/or the hospitalisation experience. Alternatively, it may be an indication of pre-existing pathological family dynamics that become overt in the health care context. Robinson and Thorne (1984) further suggest that health care providers and families belong to conceptually distinct but interdependent cultural systems, each having its own beliefs, values and attitudes. Professional health care providers are oriented towards disease while families focus on their experience with illness. Nurses, it was argued, could strengthen family "interference" by using observation and assessment skills to facilitate progression towards an alliance and by promoting family involvement. (Robinson \& Thorne, 1984).

The influence of theories from the social sciences in the development of nursing theories applicable to the family and partnerships should not be underestimated. Darbyshire (1993) suggests, however, that there is a danger in viewing the nursepatient relationship through the lens of general sociological theory. Benner (1984) mentions a "deficit mode" portrayed in the literature, as being almost uniform criticism of nurses and hospitals (Darbyshire, 1993). "Nurses are cast in the role of agents of social control and parents seem no more than passive ciphers in an institutional conspiracy, which seeks to control and oppress them" (Darbyshire, 1993:1675). Such perspectives may explain the social world but are ill equipped to recognise and describe aspects of both nurses' and parents' practices and experiences, which may be positive (Darbyshire, 1993).

Darbyshire (1993) argues that research such as that of Robinson \& Thorne (1984), which describes a forward moving, linear progression in relationships between parents and nurses, sits comfortably within a Western, scientific understanding. The concern expressed is that nurses may seize on labels to designate rather than understand parents' lived experiences. Darbyshire (1993) also highlighted the limitations of role theory, which is premised on the dualistic assumption that our being is distinct from our social practices. Darbyshire (1994) states that more recent phenomenological studies "strongly suggest that a parent's way of 'being-in-the-world' cannot be adequately captured in the objective language of roles, which suggests chosen ends rather than integrated sets of practices through which we interpret and understand ourselves and order our everyday activities". This could apply to nurses' way of 'being-in-the-world' too (author's emphasis). Role negotiation is central to the development of parent partnership but its limitations, as elements of parent partnerships, must be recognised.

\section{Family-centred care}

Coyne (1996) cites literature where a superficial understanding of the concept 'family-centred care' or descriptions of parent participation, rather than family-centred care, are rendered. According to Coyne (1996) the concept of family nursing has been generally understood to constitute nursing care given to the total family system or unit. The majority of the literature from the USA referred to the work of Shelton, Jepson \& Johnson (1987) who developed a comprehensive framework for offering family-centred care to children (Hutchfield, 1999). Shelton's framework was developed in collaboration with parents to provide family-centred care to families with children who had special educational needs (Hutchfield, 1999:1180). Family-centred care within this framework embodies a philosophy of care where family and professional partnership is evident and normalised patterns for the family are promoted.

Family-centred care in the USA has evolved from a chronic care perspective; whereas in the UK it has evolved from an acute care perspective. In the UK, Nethercott (1993) undertook a concept analysis of family-centred care, which although acknowledging the importance of viewing the family in context and respecting family diversity, focused more on supporting the functional role of the family. It appears to lack some of the mutuality demonstrated in Shelton's framework and does not emphasise family strengths (Hutchfield, 1999).

In Hutchfield's (1999) final analysis, the central tenets of family-centred care that emerged seemed to be that the child's best interest be served and that the family are considered the best party to do this. The attitude of nurses and the provision of adequate resources are also of primary importance if family-centred care is to be implemented successfully (Hutchfield, 1999). The consequences seem to be based on the assumption that both children and families will benefit from this approach. Although research suggests this, Darbyshire (1994) indicates that caring for their sick child in public can be extremely stressful for parents. Clark \& Bishop (1988) identified adequate time for communication as an essential ingredient in family-centred care in order to facilitate the teaching and supportive roles of the nurse.

\section{The reality of family-centred care}

Allen \& Petr (1998) questioned the assumption that positive developmental outcomes and overall family well being are best achieved when the service system diligently supports the abilities of families to meet the needs of their children. Family-centred care has been recognised to be a multidimensional and complex concept but Allen \& Petr (1998:8) propose that in order to arrive at a consensus definition three central and thorny issues need to be addressed: 1) how to define 'family' 2) how to set priorities and resolve conflicts among the members, and 3) how to establish the parameters of family choice. Family has commonly been defined as a nuclear family with a two-parent, biological family who reside as a household. Many children now reside in single parent families, most of 
which are female-headed and in many cultures the definition of family must include the extended family as well. These factors together with the proposal by Alan \& Petre (1998) are pivotal to the reality of family-centred care in the South African context. In South Africa and Sub-Saharan countries the reality of families without parents, due to the HIV/AIDS pandemic, needs to be considered. In these cases the responsible siblings will have to assume the traditional role of "parent" in caring for sick babies and children both in hospital and at home.

\section{Cultural dimensions of family-centred care}

Much of the literature on family-centred care from the USA and the UK is based upon "Anglo-Saxon and white American Caucasian beliefs, values and practices" (Leininger in Herbst, 1990: 20). South Africa is a multicultural society where Caucasians are in the minority. As Africans of various cultural and language groups make up the majority of the South African population, it is vital that family-centred care within their socio-cultural domain be defined. This, however, would require research to be conducted into each cultural group's perceptions of rendering family care.

In a study conducted in 1986 on 1038 black urban families in South Africa, Richter, Griesel and Etheridge found that $35 \%$ of the sample comprised nuclear families (man-pluswoman-plus-children with or without marital arrangements). A further $10 \%$ comprised single parent families (always a woman) and the remaining 55\% comprised extended families (Cleaver \& Botha, 1990:8). Traditional black families were regarded as being highly complex and presumably their structure offered substantial emotional support during earlier times. Extended family support systems (Cleaver \& Botha, 1990; Mabaso \& Uys, 1990), and the support of trusted elders in facilitating health care in the community (Chalmers, 1988; Fisher. 1987; Ntoane, 1988) in African cultural groups in South Africa have largely been eroded. Urbanisation and the apartheid system have played a central role in the erosion of these family support systems (Cleaver \& Botha, 1990) and have contributed towards socio-cultural identity crises within African family life. As black youth have become more exposed to Western values and practices through the media and improved education, these Western mores have been adopted. The impact of political change on the empowerment of families and communities and the scourge of HIV/AIDS over the past 15 years in influencing family values and cultural practices should not be underestimated. Further research would be required to explore the meaning of family in the South African socio-cultural and political context, which fall beyond the scope of this paper. However, the family in South African society appears to be in a state of crisis. This in turn will significantly impact on developing a family-centred care model for care of the sick child in South African health care institutions.

\section{Family choice in family-centred care}

In a family-centred approach, family members, not professionals, determine who constitutes the family (Allen \& Petr, 1998:8). However, family choice can undermine efforts by professionals if the family selects only certain family members to interact with the health care professionals. There are also times when in the conceptualisation of family-centred care, areas of family choice must be supported or limited. Some of the crucial areas in which family choice should be exercised include: defining the family; deciding who shall make decisions for the family; determining the unit of professional attention and the nature of the interaction; sharing information; and identifying family needs, goals and interventions. (Allen \& Petr, 1998).

This level of family choice may be threatening to professionals who are accustomed to making many of these decisions themselves, and who see themselves, rather than the family members, as the directors of the helping process (Allen \& Petr, 1998:10). This does not imply that professionals have no power or influence, as they are also governed by an ethical code of behaviour that frees them to disagree with family decisions. It also enables nurses to refuse a "service" due to lack of capability or conflict with their professional scope of practice and/or government legislation (Allen \& Petr, 1998). Self-determination cannot infringe on the rights of others and choices must be made within an ethical and legal framework that respects the rights of all parties. Nevertheless, Allen \& Petr (1998) argue that a family-centred approach requires that limits to family choice be the exception rather than the rule. The professional must communicate utmost respect for the rights and responsibilities of families to manage their own lives, and those of all their members.

\section{Fostering family strengths}

A family-centred approach must also focus on strengthening capability within families to cope with managing an ill child in an often-hostile environment (Allen \& Petr, 1998). Professionals must be aware and respect "the family's positive attributes, abilities, talents, resources and aspirations in facilitating the helping process" (Allen \& Petr, 1998:11). In fostering family strengths, Roberts \& Magrab (1991) point to the need for professionals to be sensitive to cultural diversity and identify, use and build strengths within the support networks and broader communities with which families interact (Allen \& Petr, 1998). Family strengths come in a variety of forms and may vary by race and culture. The challenge is for professionals to be "creative and open-minded in their views of what makes a particular characteristic, activity, person or group a positive contribution to a family's life" (Allen \& Petr, 1998:11).

Family-centred care is continuing to evolve but as it does, professionals in all human disciplines need to constantly evaluate whether they are prepared to not only work with families but to work for them. Whereas many professionals have been educated to focus on individuals, the family-centred approach requires them to view the whole family as the unit of attention. Although health professionals have been prepared to use their expertise to control and direct interventions, the family-centred approach on the other hand, requires the provision of information, knowledge, and options to families and then to respect decisions that the families make. Professionals will always be challenged to balance the interests of the child, respect for the family as a unit, and professional exper- 
tise Family-centred care is not a dogma to be implemented at all times but must be striven for. The incorporation of family-centred care into service delivery is dependent upon these concepts being introduced in institutions that care for sick children as well as those that educate health care professionals.

\section{Conclusion}

This literature review on family-centred care has addressed the early developments in parental care for hospitalised children, particularly as it relates to developments in the UK and USA. The evolution of the concept 'family-centred care' from its precursors patient involvement, patient collaboration, patient participation and patient partnership (substitute parent) followed. It can be concluded that the South African paediatric and neonatal nursing community are arrested at the understanding of family-centred care as parental involvement in the care of the ill infant/child. Family-centred care was defined and a cursory examination of socio-cultural and political factors influencing family life in South Africa was made. There is no separate register for the training of paediatric and neonatal nurses in South Africa and models that prioritise family-centred care do not underpin South African paediatric and neonatal nursing courses. It is therefore timely for nurses to re-evaluate family-centred care practice for hospitalised infants and children and work towards strengthening the role of the family in providing for the holistic health care needs of their members. By enhancing family-centred care for neonates and children in hospital it is anticipated that home-based care, subsequent to discharge, would yield positives outcomes for child health.

\section{References}

ALLEN, RI \& PETR, CG 1998: Rethinking family-centered practice. American Journal of Orthopsychiatry. 68(1): 4-15.

BONN, M 1994: The effects of hospitalisation on children: a review. Curationis. 17(2): 20-24.

BREWIS, E 1986: Parental prerogatives. Nursing Times. 17(24): 34-35.

BURGESS, T 1988: No more potty rounds. Nursing Times. 84(16): $69-71$.

CAHILL, J 1996: Patient participation: a concept analysis. Journal of Advanced Nursing. 24(3): 561-571.

CALLERY, P \& SMITH, L 1991: A study of role negotiation between nurses and the parents of hospitalised children. Journal of Advanced Nursing. 16(7): 772-781.

CALLERY, P 1997: Maternal knowledge and professional knowledge: co-operation and conflict in the care of sick children. International Journal of Nursing Studies. 34(1): 27-34.

CHALMERS, B 1988: The Pedi woman's experiences of childbirth and early parenthood: a summary of major findings. Curationis. 11(1): 12-19
CLEAVER, G \& BOTHA, A 1990: Experiences of motherhood: a cross-cultural study. Curationis. $13(3 \& 4)$ : 7-11.

COYNE, IT 1996: Parent participation: a concept analysis. - Journal of Advanced Nursing. 23(3): 733-740.

DARBYSHIRE, P 1993: Parents, nurses and paediatric nursing: a critical review. Journal of Advanced Nursing. 18(11): $1670-1680$

FISHER, E 1987: Multicultural midwifery. Nursing RSA. 2(11): $36-39$

HALL, DJ 1978: Bedside blues: The impact of social research on the hospital treatment of sick children. Journal of Advanced Nursing. 3(1): 25-37

ARDGROVE, C \& ROBERTS, BM 1989: The family with a hospitalised child. (In: Towards a science of family nursing: Gilliss, C.L., Highley, B.L., Roberts, B.M. et al. California: Addison-Wesley Publishing Company, pp. 248-260.

HERBST, MC 1990: Transcultural nursing. Nursing RSA. 5(9): 20-23.

HUTCHFIELD, K 1999: Family-centred care: a concept analysis. Journal of Advanced Nursing. 29(5): 1178-1187.

KEANE, S., GARRALDA, M \& KEEN, J 1986: Resident parents during paediatric admissions. International Journal of Nursing Studies. 23(3): 247-253.

LEARY, PM 1973: The South African child in hospital. $\underline{\text { South }}$ African Medical Journal. 47(15): 647-648.

LERWILL, CJ 1983: Preparation of children for hospitalisation at the Johannesburg Hospital. Curationis. 6(3): 4-7.

MABASO, MS \& UYS, LR 1990: The experience of black parents/caretakers with the births and care of a child with profound congenital defects. Curationis. 13(1 \&2): 33-36.

NETHERCOTT, S. 1993: A concept for all the family. Family-centred care: A concept analysis. Professional Nurse. 8(12): 794-797.

NTOANE, C 1988: Traditional birth attendants in Bophuthatswana (Bo-mmaabotsetse). Curationis. 11(3): 2023.

ORR, JP 1994: The hospitalisation of young children: historical overview and current South African practice. Pedmed. $7(5)$ : $26-36$.

PALMER, SJ 1993: Care of sick children by parents: a meaningful role. Journal of Advanced Nursing, 18(2): 185-191.

PILLAY, AL \& PILLAY, P. 1988: Emotional aspects of paediatric hospitalisation: guidelines for management. Nursing RSA. 3(1): 25-26.

RANGAKA, M; ROSE, C \& RICHTER, L 1993: Depres- 
sive symptomatology in hospitalised children. Curationis. 16(2): $40-44$.

ROBINSON, CA \& THORNE, S 1984: Strengthening family interference. Journal of Advanced Nursing. 9(6): 597-602.

SHELTON, T; JEPSON, E \& JOHNSON, B 1987: Family-centred care for children with special health care needs. Association for the Care of Children's Health. Washington, District of Columbia.

SWANWICK, M 1983: Platt in perspective. Nursing Times. 79(2): 5-8.

WEBB, N, HULL, D \& MADELEY, R 1985: Care by parents in hospital. British Medical Journal. 291(6489): 176177. 